\title{
Soft-MS and Computational Mapping of Oleuropein
}

\author{
Luigi Gentile ${ }^{1,2}$, Nicola A. Uccella ${ }^{3,4}$ and Ganapathy Sivakumar ${ }^{5, *}$ \\ 1 Chemistry and Chemical Technology Department, University of Calabria, P. Bucci 12C, 87036 Rende, Italy; \\ luigi.gentile@biol.lu.se \\ 2 MEMEG, Department of Biology, Lund University, 22362 Lund, Sweden \\ 3 DIMEG Department, University of Calabria, P. Bucci 42C, 87036 Rende, Italy; nicola.uccella@unical.it \\ 4 IRESMO Foundation Group, via Petrozza 16A, 87040 Montalto Uffugo, Italy \\ 5 Department of Engineering Technology, College of Technology, University of Houston, \\ Houston, TX 77204, USA \\ * Correspondence: sganapa3@central.uh.edu; Tel.: +1-71-3743-0497; Fax: +1-71-3743-0172
}

Academic Editors: David Arráez-Román and Ana Maria Gómez Caravaca

Received: 4 April 2017; Accepted: 2 May 2017; Published: 6 May 2017

\begin{abstract}
Olive oil and table olives are rich sources of biophenols, which provides a unique taste, aroma and potential health benefits. Specifically, green olive drupes are enriched with oleuropein, a bioactive biophenol secoiridoid. Olive oil contains hydrolytic derivatives such as hydroxytyrosol, oleacein and elenolate from oleuropein as well as tyrosol and oleocanthal from ligstroside. Biophenol secoiridoids are categorized by the presence of elenoic acid or its derivatives in their molecular structure. Medical studies suggest that olive biophenol secoiridoids could prevent cancer, obesity, osteoporosis, and neurodegeneration. Therefore, understanding the biomolecular dynamics of oleuropein can potentially improve olive-based functional foods and nutraceuticals. This review provides a critical assessment of oleuropein biomolecular mechanism and computational mapping that could contribute to nutrigenomics.
\end{abstract}

Keywords: biophenols; $\beta$-glucosidase; hydroxytyrosol; olive oil; secoiridoid; table olives; tyrosol

\section{Introduction}

Olive oil is extracted from olive drupes which have several health benefits and is one of the stable bioactives in the Mediterranean diet [1]. The green olive drupes are rich in biophenol secoiridoids such as oleuropein, demethyloleuropein, ligstroside, and their hydrolytic derivatives such as oleuropein aglycone, elenolate, oleoside-11-methyl ester, elenoic acid, hydroxytyrosol, and tyrosol (Figure 1) [2]. Oleocanthal and oleacein present in virgin olive oil that are dialdehydic isomeric forms of ligstroside and oleuropein aglycones, respectively, which have anticancer properties [3,4]. These are biosynthesized as combomolecules between the functional groups of biophenol secoiridoids (BPsecos). They are characterized by a chimeric structure with two chiral centers, $\mathrm{C} 1$ and $\mathrm{C} 5$ in the secoiridoid moiety. Their glucoside functionality is released via specific enzyme action by native $\beta$-glucosidase but is resistant to acidic environment $[5,6]$. This could result from the extended delocalization of molecular orbitals, which decreases the basicity of the glucosidic oxygen against its protonation and the facile aglycone release. The first concerted step of hydrolysis is by the native $\beta$-glucosidase. This is assisted by the enzymatic catalysis exerted onto the glucosidic oxygen. Moreover, these BPsecos are more effective than either of the separate moieties, each characterized by radical reactivity from hydroxyaromatic groups and by competing polar reactions from the secoiridoid moiety after aglycone release. Oleuropein and its isomeric oleuroside are biosynthesized via loganin route linked to the hydroxytyrosol, while in ligstroside analogue, the BP moiety is tyrosol. Hydroxytyrosol and tyrosol are also bioactives of extra virgin olive oil and table olives, which could prevent metabolic syndrome 
and inhibit the paracrine regulation of tumor necrosis factor- $\alpha$-induced endothelial cell migration via reduced glioblastoma cell cyclooxygenase-2 expression $[7,8]$.
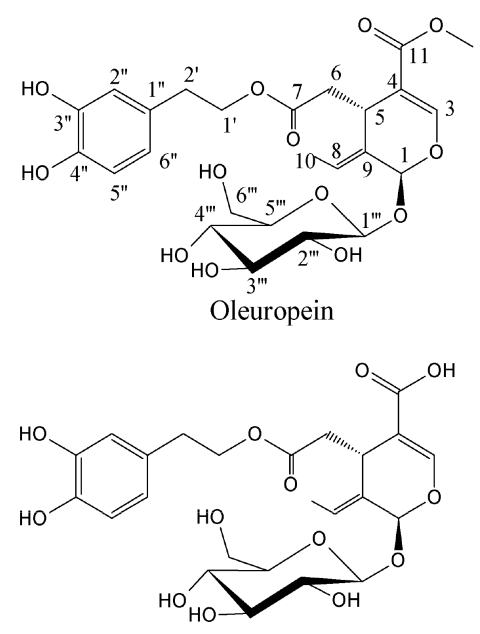

Demethyloleuropein

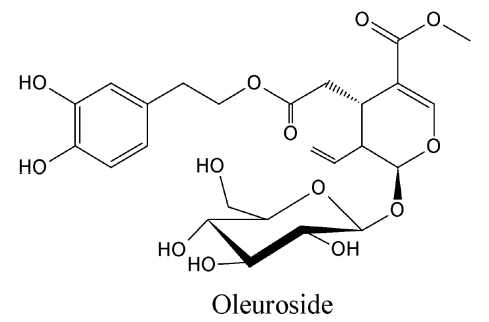<smiles>O=C(O)C1=COC(O)C2COC(OCCc3ccc(O)c(O)c3)CC12</smiles>

Oleuropein aglycone
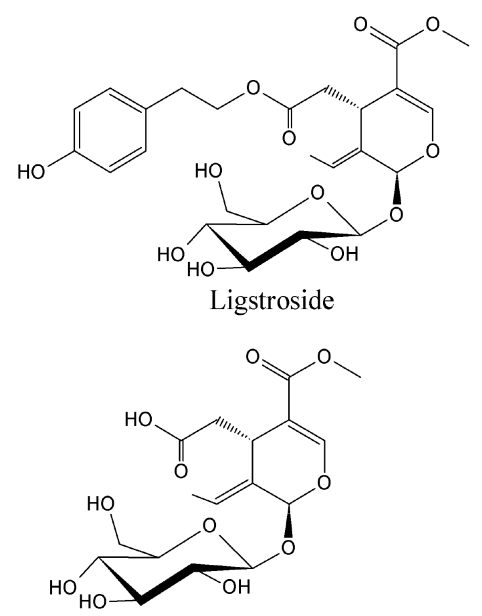

Oleoside-11-methyl ester<smiles>COC(=O)C1=COC(C)C(C=O)C1CC(=O)O</smiles><smiles>OCCc1ccc(O)c(O)c1</smiles>

Hydroxytyrosol<smiles>OCCc1ccc(O)cc1</smiles>

Tyrosol

Oleacein<smiles>C/C=C(/C=O)C(CC=O)CC(=O)OCCc1ccc(O)c(O)c1</smiles>

Elenoic acid<smiles>CC(=O)C(CC=O)CC(=O)OCCc1ccc(O)cc1</smiles>

Figure 1. Molecular structures of olive biophenol secoiridoids.

Thus, significant efforts have been devoted to the investigation of these olive chimeric bioactives, which incorporate the key features of free radical quencher in the catechol moiety of the hyroxytyrosol esterified to the oleoside-11-methyl ester and are active for the polar biomolecular dynamics. This is the seco-precursor of oleacein and oleocanthal. Their dialdehydic carbonyl groups along with the $o$-quinone after the free radical reaction of hydroxytyrosol, are effective sites for DNA alkylation, protein arylation and denaturation, induced by catecholase and $\beta$-glucosidase reactions [9-11]. However, hydroxytyrosol and oleoside-11-methyl ester are stored in the phytoanticipin, the inactive and safe form of BPseco, stabilized as glucoside to increase solubility. BPsecos revealed stable to acid because of their chimeric structure, but less to base due to catechol and phenol units. These are compartmentalized in the vacuoles of olive mesocarp cells, while the $\beta$-glucosidase is kept in chloroplasts [12,13]. Analytical methodologies have provided information into the molecular reactivity of oleuropein [14-18]. Recent transcriptomic, stem cells, and clinical data suggests that oleuropein could prevent obesity, osteoporosis, and neurodegeneration [19-21]. It can be potentially standardized in Mediterranean functional foods and used in nutraceuticals [22]. Enhancement of bioactives in olive oil and table olives is a growing area of interest in nutrigenomics with requiring doses of antioxidants like hydroxytyrosol and tyrosol [23-25]. Therefore, oleuropein has been thoroughly evaluated and quantified as precursor of its hydrolytic bioactives [26-28]. Biomolecular approaches exploiting complex hyphenated high performance liquid chromatography electron spray ionization mass spectrometry (HPLC-ESI-MS) were used for these natural bioactive assessments [29]. The goal of this review is to highlight biomolecular dynamics and computational mapping of oleuropein. 


\section{Molecular Dynamics of Oleuropein}

The molecular mechanism of the olive BPseco was examined under ESI-MS and the MS/MS analysis by collision activated dissociations (CAD) [17]. The $\mathrm{p} K_{1 \mathrm{a}} 9.25$ and $\mathrm{p} K_{2 \mathrm{a}} 13.00$ of catechol moiety, $\mathrm{p} K_{1 \mathrm{a}}=9.10$ and $\mathrm{p} K_{2 \mathrm{a}}=9.92$ measured values, deserved the negative mode under soft ionization conditions at $-28 \mathrm{~V}[30,31]$. These are more sensitive than positive ionization by $20-50 \mathrm{fold}$, even if sometimes used for quantitation [32-35]. Under soft ionization experiments, oleuropein resulted in the formation of $m / z 539$, a pseudomolecular ion, as the lonely base peak of the ESI-MS spectra, while the CAD product ions were abundant (Figure 2). Under CAD experiments, oleuropein- $\mathrm{H}^{-}$, $m / z 539$, base peak being $m / z 307,79 \%$, dissociated to $m / z 377$, oleuropeinenal-(E)-enol- $\mathrm{H}^{-}$, and the neutral glucose- $\mathrm{H}_{2} \mathrm{O}, \mathrm{mw}=162$. A 1,5- $\mathrm{H}$ shift at a six member transition state is favorable for the quasi-aromatic array of three electron pair synchronous reorganization (Figure 3). Instead, BPseco $+\mathrm{H}^{+}$, $m / z 541$, revealed small pseudomolecular-ions, competitively fragmenting to analog $m / z 379$ and to the base peak $m / z 361$ in positive mode and fast atom bombardment (FAB) spectra [32,34]. Since pseudomolecular ions populated highly energized levels, protonation on different basic sites controlled the overall reactivity gas phase oleuropein $+\mathrm{H}^{+}$. In fact, glucose was eliminated to $m / z 361$ from probable $\mathrm{H}-\mathrm{C} 10$-methyl migration to the extensive conjugated $\mathrm{C} 11$-carbonyl $+\mathrm{H}^{+}$. Further, unimolecular dissociations of $m / z 377$ from oleuropein $-\mathrm{H}^{-}$could be intramolecular Ei-eliminations, pericyclic from its $\gamma-\mathrm{H}$ to carbonyls, then $m / z 307$ and $m / z 275$ as syn-eliminations of neutral 70 and $102 \mathrm{mws}$, respectively (Figure 3). Oleosidate-11-methyl ester at $m / z 403,2.1 \%$, is also formed with neural semiquinone-like products. A gas-phase base-like hydrolysis generated a cascade of consecutive processes to $m / z 223$ aglycone and glucose followed by $m / z 179$ at very high energy. An identical pattern was recognized for oleuroside- $\mathrm{H}^{-}$in ESI-MS/MS, dissociating to $\mathrm{m} / \mathrm{z} 377, \mathrm{~m} / \mathrm{z} 307$, and $m / z 275$, with $m / z 223$ and $m / z$ 179. This molecular dynamics of chimeric oleuropein model replicated the large site selectivity in base-catalyzed hydrolysis [36].

The olive oil milling process, simulated under acid catalysis at $\mathrm{pH}=4.2$ for $120 \mathrm{~min}$ at $35^{\circ} \mathrm{C}$, provided intact oleuropein without any hydrolytic reaction of the two ester groups, preventing any oxidative degradation of the hydroxytyrosil to the corresponding o-quinone group followed by polymerization [31,37]. The BPseco remains almost intact under the table olive procedure, $\mathrm{pH}=8.0$ and 9.0 for $240 \mathrm{~min}$ at $25^{\circ} \mathrm{C}$. Thus, the BPseco change observed through table olive processing derives from microbiota action as lactic fermentation [38]. A complex degradation process of BPsecos is revealed at higher basicity at $25^{\circ} \mathrm{C}$ (i.e., $\mathrm{pH}=11.1,12.8$ and 13.2 for 120,60 and $60 \mathrm{~min}$, respectively). The formation of hydroxytyrosol and olesoside-11-methyl ester are found along with competing molecular dynamics at experimental $\mathrm{pH}=12.7$ for $40 \mathrm{~min}$ in nuclear magnetic resonance (NMR) mode [36]. However, complete hydrolysis on the methyl ester group at C-11 after further addition of base gave the oleoside as minor products (Figure 4) [39]. This process is governed by a large site selectivity, similar to the enzymatic degradation in olives drupes at the maturity stage, which avoids the apparent less hindered ester group of the BPseco chimeric structure [36].

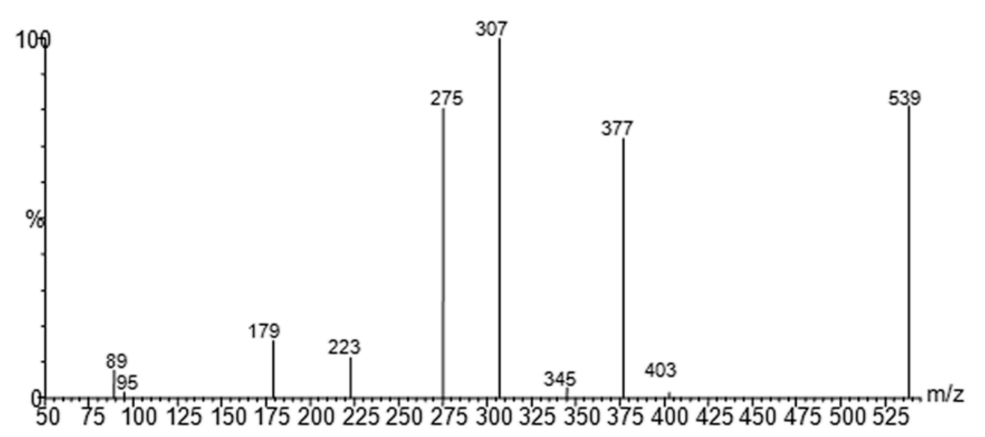

Figure 2. Negative ion ESI-MS/MS spectra of oleuropein [17]. 


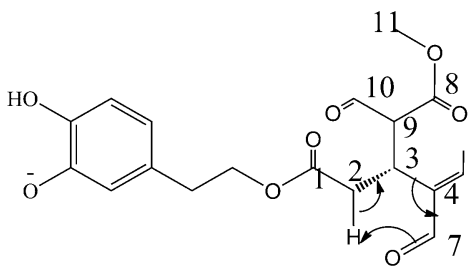

$\mathrm{m} / \mathrm{z} 377$ rotamer $a$<smiles>C=C(C=O)C(C=O)C(C=O)C(=O)OCCc1ccc(O)c(O)c1</smiles>

$\mathrm{m} / \mathrm{z} 377$ rotamer $b$<smiles>CC=C=COC(=O)C=CC(C=O)C(=O)OC</smiles>

$\mathrm{m} / \mathrm{z} 307$

$70 \mathrm{mw}$<smiles>O=Cc1ccc(OCCc2ccc(O)c(O)c2)o1</smiles>

$\mathrm{m} / \mathrm{z} 275$<smiles>CO/C(O)=C\C=O</smiles>

$102 \mathrm{mw}$

Figure 3. Collision activated dissociations (CAD) dissociations of oleuropein pseudomolecular anion, $m / z 539$

The $\mathrm{C} 11$ ester carbonyl has not a simple electron distribution, but the highly extensive conjugation to the acetal $\mathrm{O} 2$ group is affected by inductive effect exerted by the glucoside oxygen [13]. Thus, the electron density effect on BPseco functionality, obscured the steric hindrance on C7 ester and determined the site selectivity under basic mode as well as highly acid resistance [36]. The true chimeric nature of the BPseco controlled the rate determining dynamics in activating the two major processes as polar and radical mechanisms. In polar mode, the base-catalyzed acyl-oxygen fission via a biomolecular reaction leads to the hydrolysis of oleuropein on the ester group at C7. In radical conditions, the $\mathrm{C} 11=\mathrm{O}$ reactivity competes with the $\mathrm{pH}$ controlled electron donor capacity of the catechol unit, thus resulting in aerial autoxidation.

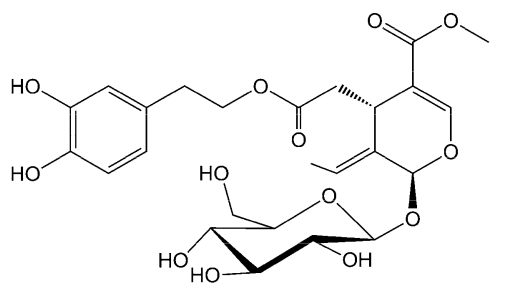

Oleuropein

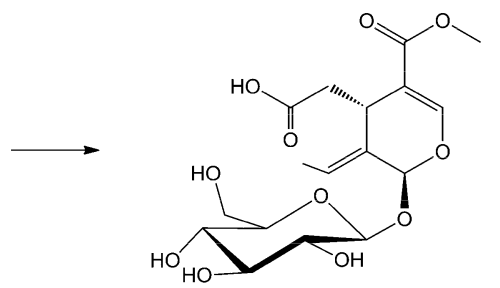

Oleoside-11-methyl ester

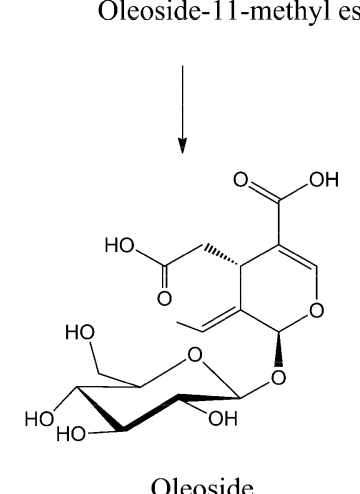

Oleoside<smiles>OCCc1ccc(O)c(O)c1</smiles>

Hydroxytyrosol

Figure 4. Polar hydrolytic sequence of oleuropein under basic catalysis, competing with radical processes. 
The radical autoxidation of the BPsecos and hydroxytyrosol was consistently observed above $\mathrm{pH}=11.1$, rising oleuropein dimers (Figure 5). A head to tail structure of the oligomerization mechanism takes place when polyphenol oxidase (PPO) is mixed with BPseco substrates under atmospheric $\mathrm{O}_{2}$ [40]. The initial transformation requires several steps leading to the $o$-quinone-like hydroxytyrosil residue from oleuropein after extended autoxidation, either by catalytic or enzymatic processes. This results in the oligomerization from addition reactions of oleuropein aromatic OHs on the enone of o-quinone-like moiety followed by tautomerisation to restore the aryl ring. The BPseco oligomerization could be the alternative pathway to the cyclization undergone by dimers of hyroxytyrosol in the peculiar methanoxocinobenzodioaxinone ring structure of the $\mathrm{BP}$ [41]. On the other hand, severe physico-molecular conditions were required for oleuropein hydrolysis associated with low yields, when $1 \mathrm{~N} \mathrm{H}_{2} \mathrm{SO}_{4}$ at $100{ }^{\circ} \mathrm{C}_{\text {or }} \mathrm{H}_{2} \mathrm{SO}_{4}$ at $\mathrm{pH}=0$ for $3 \mathrm{~h}$ at $55{ }^{\circ} \mathrm{C}$ [42-44]. The reaction products were hydroxytyrosol, elenoic acid, hydroxytyrosil elenolate, and glucose. Significantly different environments were experienced for iridoid hydrolysis, lacking the dihydropyranyl arrangement $[45,46]$. However, the exact molecular dynamics of oleuropein is largely dependent on its structural heterogeneity towards polar and radical reactivity. Nevertheless, its biological properties should even be the direct consequence of the two major functionalities, secoiridoid and biophenol, the latter associated to its acidity dissociation constants and redox potentials.<smiles>[R]OCCc1ccc(O)c(O)c1</smiles>

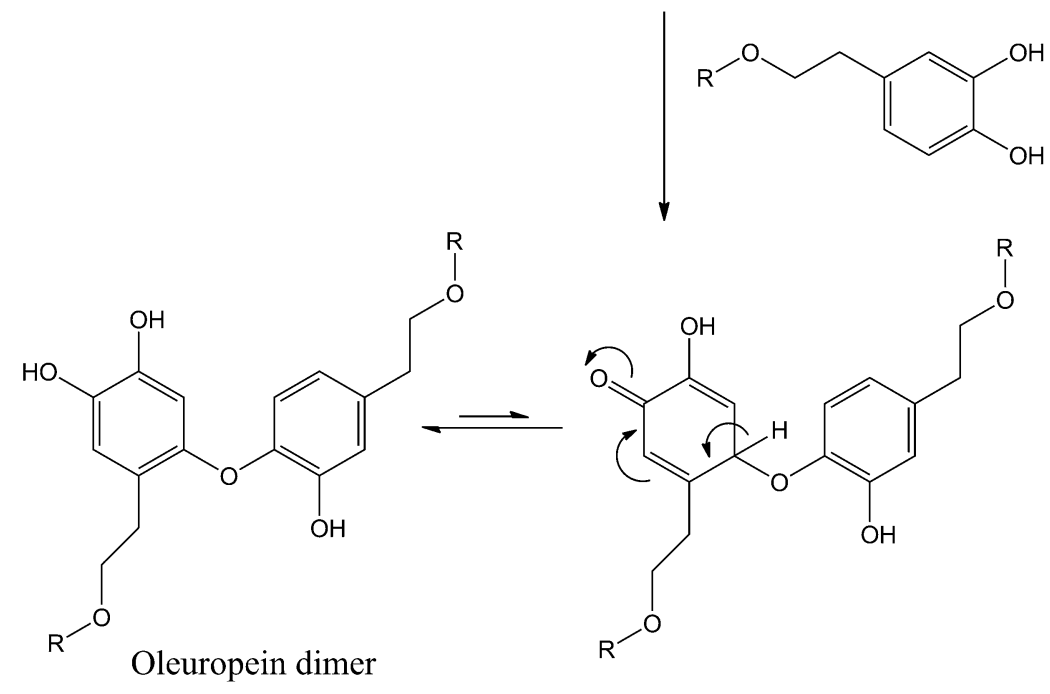

Figure 5. Reaction dynamics for the oligomerization of oleuropein under autoxidation, where $R=$ Oleoside.

On a thermodynamic basis, the autoxidation process of oleuropein and its BPseco analogs could be inefficient as it was ascertained at $\mathrm{pH}=1.5$ to 6.0. The exception operates at $\mathrm{pH}=6.2$, because of heavy metals and Cu contained in PPO enzyme. The enzyme activity increases with the highest amount of oleuropein during olive drupe ripening [47]. Nevertheless, BPsecos were very stable even at strong acidic $\mathrm{pH}$ [48]. Indeed, oleuropein and its BPseco analogs confirmed a high susceptibility to autoxidation at high $\mathrm{pH}$ values. The lower the one-electron reduction potential of $\mathrm{BP}$ semi-reduced free radical/reduced forms, the easier their oxidation under the $\mathrm{O}_{2} / \mathrm{O}_{2}{ }^{-}$redox system. Therefore, the chimeric oleuropein preserves its original combomolecular structure towards important bioactive dynamics, under polar and free-radical modes [49]. In fact, oleuropein considered a quite evident simple acetal group, which appears very stable at specific acidic conditions or when mimic with natural $\beta$-glucosidase simulation [50]. In addition, $\mathrm{H}^{+}$and $\mathrm{H}^{-}$transfer shows a distinct behavior for 
BPs, latter associated with chain breaking dynamics with potent scavenger action on hydroxyl and superoxide radicals as well as peroxynitrite [51,52].

BPsecos become phytoalexins when expressed by enzymatic reactions for the conversion to cyclic enones by PPO and anales as well as enales by $\beta$-glucosidase [13]. Esterases could intervene at olive drupes maturity stage with demethylation to demethyloleuropein at the carboxylate $\mathrm{C} 11$ and selective ester hydrolysis at the carboxylate $\mathrm{C} 7$ followed by further degradation to Cannizzaro-like metabolites and oleacein, reported as 3,4-DHPEA-EDA [2-(3,4-hydroxyphenyl) ethyl (3S,4E)-4-formyl-3-(2-oxoethyl)hex-4-enoate] [53,54]. After enzymatic processes, BPseco phytoalexin damages several macromolecules such as DNA and proteins, via alkylation and nucleophyle-carbonyl coupling. The nucleophilic dynamics at macromolecular reactive sites provides carbonyl oxygen loss to lysine alkylation, protein denaturation, and protein cross linkage [13]. The large resistance of oleuropein and its BPseco analogs towards specific acid-catalyzed hydrolysis requires a rational interpretation, which could be same structural effects that control their base-catalyzed reactivity. The oleuropein hydrolysis considers a simple reaction of its acetal-glucoside with the specific acid-catalyzed rupture of two carbon-oxygen bonds at $\mathrm{C} 1$ followed by water addition to the leaving glucose of BPsecos, which replaced by several proton-transfers originated from the basic site on $\mathrm{C} 11=\mathrm{O}$ (Figure 6) [55]. The overall dynamics involves a multistep pathway with pre-equilibrium of $\mathrm{H}_{3} \mathrm{O}^{+}$and $\mathrm{C}=\mathrm{O}$ base, external to the BPseco-ring and $\mathrm{H}_{2} \mathrm{O}$ linkage to $\mathrm{C} 3$-ring. A determining step follows by C1-OGlu bond cleavage at the transition state, leading to easy glucose released because of the resonance stabilized carboxonium at $\mathrm{C} 1$. Also, the concerted seco-ring opening to $\mathrm{C} 1$-enol, collapsing the dialdehyde form of oleuropeindiale and ligstrodidediale from oleuropein and ligstroside or to oleacein and oleocanthal from their demetylated derivatives, respectively.

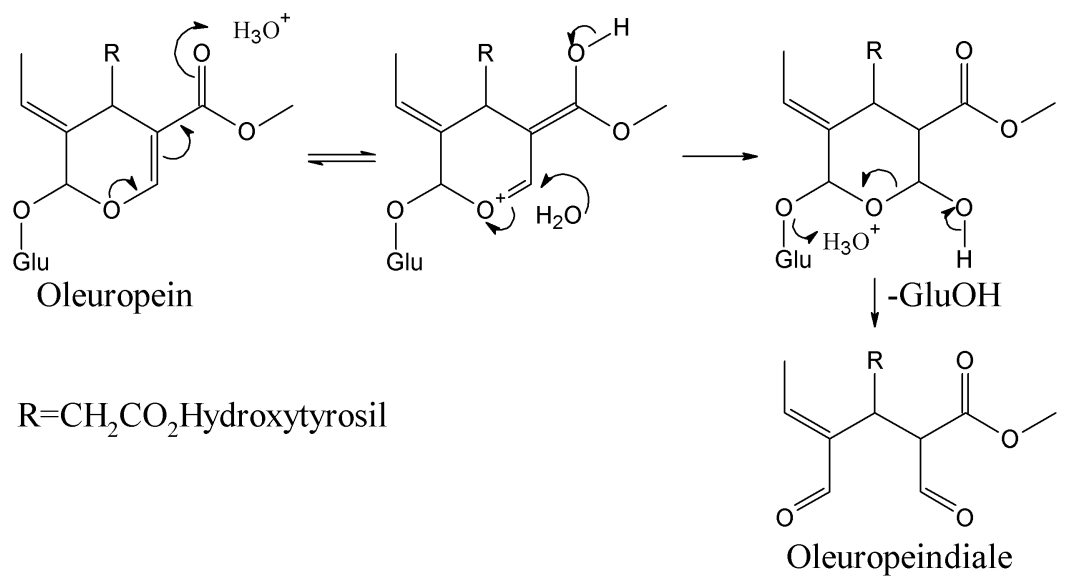

Figure 6. Acid-catalyzed hydrolysis of oleuropein.

The substitution pattern of the conjugated system $\mathrm{O} 2-\mathrm{C} 3=\mathrm{C} 4-\mathrm{C} 11 \mathrm{O}_{2} \mathrm{Me}$ with its electron withdrawal of the seco-acetal group on $\mathrm{O} 2$ lowers the basicity of exo-OGlu. Thus, $\mathrm{H}^{+}$transfer is incomplete at the transition state and explains the great decrease of reactivity experienced by BPsecos. Along the same direction, the increased stability on the corresponding $\mathrm{C} 1$ carbenium ion transient moiety is directly related to the hydrolysis rate of BPsecos. Therefore, the electron withdrawal from O2 occurring on the acetal OGlu of oleuropein decreases the equilibrium concentration of intermediate protonated on the same OGlu, making the departure of glucose as a leaving group less prone because of the further destabilization of eventual C1-carboxonium group. Therefore, the dynamics of proton transfer towards the basic site onto the $\mathrm{C} 11=\mathrm{O}$ carbonyl leads to the conjugate addition $\mathrm{H}_{2} \mathrm{O}$ nucleophile on the $\alpha, \beta$ unsaturated carbonyl moiety of the BPseco ring as a 1,4-addition to $\beta$-C 3 with the largest coefficient on the lowest unoccupied molecular orbital (LUMO) of oleuropein molecular system towards the thermodynamic product. This evolves with consequent bond cleavage for the 
novel approach to BPseco dynamics and to the bioactive hydrolytes found in green olives drupes and olive oil [56].

This dynamic mechanism is far from a simple step-by-step transformation of oleuropein starting material to its hemiacetal on C3 and to oleuropeindiale under acid-catalyzed reactions $[57,58]$. The development of a cascade conversion in concert provides the recovery of hydroxytyrosil elenolate without any possible isolation of intermediates [43]. These BPsecos are reactive open cycle species rapidly undergoing ring closure via a Michael-type process to the six-membered structure hydroxytyrosil elenolate (Figure 7). It is one of the most abundant BPseco derivatives found in olive waste water after acid hydrolysis [59]. However, the rate of cyclization depends on their substituents. For instance, the lack C11-carboxymethyl in oleacein from demethyloleuropein or the $\pi$-bond on $\mathrm{C} 9$ shifted to $\mathrm{C} 8$ in oleuroside slows down the overall dynamics to elenolate ring formation, since the electron withdrawn exerted by the C11-carboxymethyl lessens the nucleophilic attitude of C3-enol $[2,6,60,61]$. Therefore, the acetal hydrolysis of oleuropein at its seco-site is easy and rapid exclusively when activated by its native $\beta$-glucosidase [62].

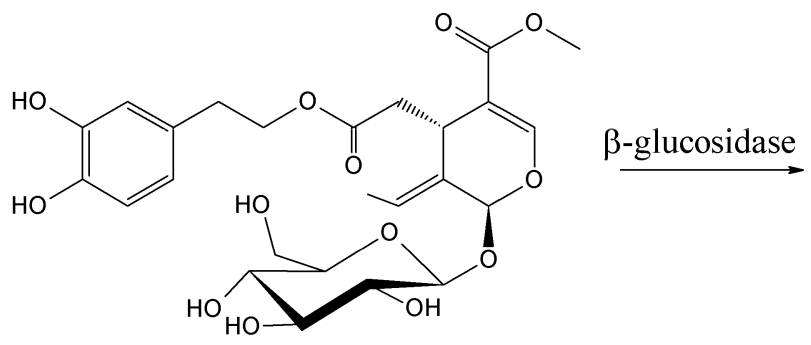

Oleuropein<smiles>COC(=O)C1=CC=CC(C(=O)O)[C@@H]1CC(=O)OCCc1ccc(O)c(O)c1</smiles>

Oleuropein-E-enol<smiles>COC(=O)C1=COC(C)C(C=O)[C@H]1CC(=O)OCCc1ccc(O)c(O)c1</smiles>

Hydroxytyrosil elenolate

Figure 7. The cascade dynamics of oleuropein to hydroxytyrosil elenolate in concert under acid-catalyzed conditions.

\section{Computational Mapping of Oleuropein}

For computational mapping of oleuropein, the ab initio semi-empirical self-consistent-field (SCF) hartree-fock HF calculation was carried out employing 6-311G(d,p) basis set. Geometry was optimized at the HF/6-311G(d,p) level. The coefficients of the frontier molecular orbitals were obtained from the HF/6-311G $(d, p)$ optimized geometries. The 6-311G $(d, p)$ generated highest occupied molecular orbital (HOMO) and LUMO molecular orbitals of 1-3. The ab initio method with the HF/6-311G(d,p) geometrical optimization is more accurate than Austin model 1 (AM1), which uses a minimal basis set of valence Slater type s and $\mathrm{p}$ in an atomic orbital to extend valence-electron molecular orbitals [17]. $\mathrm{Ab}$ initio methods are better for energetics evaluation. The remarkable molecular framework distributes HOMO and HOMO-1 for radical processes and HOMO-2 for electrophilic site. LUMO is clearly the polar molecular dynamics, devoted to the nucleophilic reaction (Figure 8). At $\mathrm{pH}=7.0$, oleuropein unveils a very low dissociation $(0.2 \%)$ according to calculated values for its $\mathrm{p} K_{\mathrm{a} 1}=9.70 \pm 0.10$, which involves the 3-OH on the aryl group as performed adopting the Hammett-type equation. This allowed utilization of apparent $\mathrm{p} K_{\mathrm{a}}$ values, thus mimicking the experimental order of deprotonation in the hydroxytyrosol residue of oleuropein in water solution [63,64]. The earlier $\mathrm{p} K_{\mathrm{a} 1}=9.07 \pm 0.02$ and $\mathrm{p} K_{\mathrm{a} 2}=9.98 \pm 0.06$ showed for catechol were 9.25 and 13.0, respectively [30,65]. Calculated $\mathrm{p} K_{\mathrm{a} 2}$ gave 
then $12.52 \pm 0.20$ for 4-OH aryl, which renders oleuropein barely mono-deprotonated in the neutral environment with $\mathrm{p} K_{\mathrm{a} 3}=12.80 \pm 0.70$ at $2^{\prime}, \mathrm{p} K_{\mathrm{a} 4}=13.54 \pm 0.70$ at $4^{\prime}, \mathrm{p} K_{\mathrm{a} 5}=14.48 \pm 0.10$ at $6^{\prime}$, and $\mathrm{p} K_{\mathrm{a} 6}=14.81 \pm 0.70$ at $3^{\prime}$ on the glucose moiety of oleuropein. The mono-deprotonated oleuropein- $\mathrm{H}^{-}$ generated during the ESI-MS localized the negative charge on the 3-aryloxy site as an alternative to the $\mathrm{p} K_{\mathrm{a} 4}=13.54 \pm 0.70$ at $4^{\prime}$ which is similar to verbascoside $[30,66,67]$. The two $\mathrm{OH}$ aryl groups at 3 and 4 positions of the 3,4-dihydroxyphenyl residue are not equivalent as in the catechol molecule. This is shown by the SCF molecular orbital calculations on hydroxytyrosol, which was optimized at the AM1 level where the highest positive excess charge accumulated on the $\mathrm{H}$ bonded to $\mathrm{O}$ at 4 in the hydroxytyrosol ring [51]. This specifies, the primary transfer attitude due to a free radical dynamics of its main bioactivity, i.e., the scavenging of reactive oxygen and nitrogen species, the major cause of several human degenerative diseases.

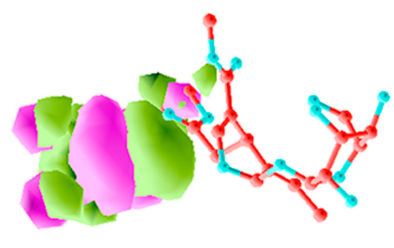

$\mathrm{HOMO}=-8.173 \mathrm{eV}$

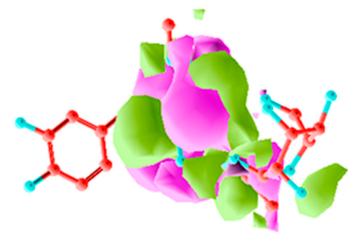

$\mathrm{LUMO}=2.786 \mathrm{eV}$

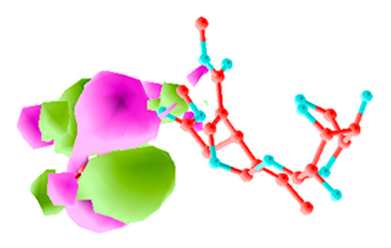

HOMO-1 $=-9.03 \mathrm{eV}$

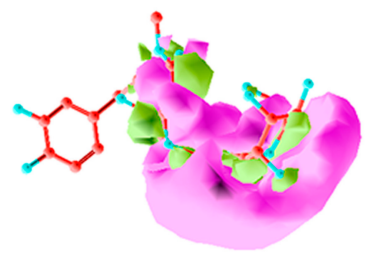

$\mathrm{LUMO}+1=3.066 \mathrm{eV}$

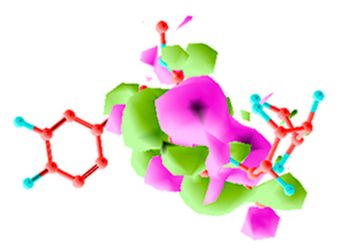

HOMO-2 $=-9.853 \mathrm{eV}$

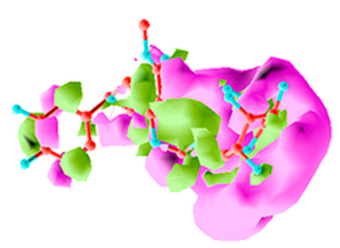

$\mathrm{LUMO}+2=3.268 \mathrm{eV}$

Figure 8. Oleuropein orbital surfaces and energy levels for highest occupied molecular orbital (HOMO), HOMO-1, HOMO-2, and lowest unoccupied molecular orbital (LUMO), LUMO+1, LUMO+2 using ab initio calculation with the 6-311G $(\mathrm{d}, \mathrm{p})$ basis set. Isosurface of the HOMO and LUMO consists of two colors (green and pink), which represents the positive and negative isosurfaces. The choice of color for positive or negative part is arbitrary.

The BPseco offered its bident functionality of ester site to the alternative release of hydroxytyrosol and methanol from position $\mathrm{C} 7$ and $\mathrm{C} 11$ respectively. Thus, the longstanding conjugation is from $\mathrm{O} 2$ until $\mathrm{C} 11=\mathrm{O}$ changed the overall dynamics of carbonyl esters and acetal groups because $\mathrm{C} 11$-ester differs from the $\mathrm{C} 7$ as electronic and steric structures. The same happened to the acetal group, which was not a simple but a conjugated system. The combo-functionality of BPseco provided perturbated molecular orbitals due to reciprocal conjugation represented at HOMO $-8.173 \mathrm{eV}$ and LUMO $2.786 \mathrm{eV}$ calculated with ab initio SCF and 6-311G(d,p) basis set (Figure 8). Ab initio computational methods are quite reliable for small and medium-sized molecules. Semi-empirical molecular orbital shown $-8.669 \mathrm{eV}$, and, -0.111 for HOMO and LUMO, respectively. The HOMO value is essentially the same, while the LUMO is highly underestimates by the semi-empirical method AM1. Semiempirical AM1 underestimate the normal component of the polarizability tensor, the first hyper polarizability tensor strongly depends on the electronic structure of BPsecos. As a consequence, the HOMO-LUMO calculations are affected. The observed HOMO-LUMO gap is $5.387 \mathrm{eV}$, which means the BPseco absorbs in the UV. Oleuropein molecular dynamics is rationalized by HOMO electron distributions, thus the low reactivity of oleuropein under strong acid catalysis is prevented, requiring the general acid-base environment. Specifically, the acid-base catalysis for the $\mathrm{H}^{+}$induction of hydrolytic reaction on BPsecos is in competition between $\mathrm{C} 11=\mathrm{O}$ and the forbidden site on the hydroxytyrosil moiety unreactive under this condition being only available for electrophilic aromatic substitutions. Therefore, the reaction rate is not dependent only on $\mathrm{pH}$ but is also a function of $\mathrm{H}^{+}$buffer concentrations. 
The buffer aids in stabilizing the transition state via donation of $\mathrm{H}^{+}$onto $\mathrm{C} 11=\mathrm{O}$. The reaction rate depends on the buffer concentration as well as on the appropriate $\mathrm{H}^{+}$site at the transition state. The largest coefficient of conjugated system in oleuropein LUMO resides on the $\mathrm{C} 3$, the soft $\beta$-carbon of the $\alpha-\beta$ unsaturation of BPseco. Thus, the $\mathrm{HO}^{-}$nucleophile attack occurs at $\mathrm{C} 7=\mathrm{O}$ site because the electrostatic control is dominant due to the lowest charge density of its LUMO. Therefore, both HOMO and HOMO-1 on the hydroxytyrosil moiety, which appear to be highest in their energy states compared to HOMO-2. Oleuropein reveals its first facile dynamic behavior toward radical reaction as free radical quencher and then as polar electrophiles through carbonyl groups on the newly formed aldehydes and o-quinone-like moiety. This key orbital interaction establishes the start-up step for BPseco hydrolysis leading to the fission of combo-oleuropein, which lose its functional complexity responsible for the radical reactivity and leaving alone the molecular structure for the polar reaction.

\section{Conclusions}

The quality olive oil and table olive production involves complex BPsecos molecular dynamics. Therefore, understanding the molecular mechanism of oleuropein and its analogs such as ligstroside, demethyloleuropein and oleuroside along with their bioactives oleacein, oleocanthal and elenolates could improve the olive processing and functional food characteristics of bitterness, pungency, and astringency. Overall, the native enzymatic reaction cascade lasted a short time, which is different from acid-catalyzed mechanism. The olive oil extraction from drupes using crushing and malaxing process for $15-90$ min at $25-35{ }^{\circ} \mathrm{C}$, reveals a sufficiently large reduction of catechol-like BPs to $70 \%$ due to their oxidation by PPO. Indeed, temperature negatively influences quality attributes. HOMO and LUMO computational mapping provide molecular dynamics for bioactives coming from oleuropein and pave the way to further experiments on nutrigenomics. Thus, good manufacturing practice is part of the quality control system, which offer enormous health beneficial rich biomolecules containing olive oil and table olives for advanced functional foods and nutraceuticals.

Acknowledgments: The IRESMO foundation gratefully acknowledges Olitex-Fair CT-3053 European Union financial support. GS thanks the Global Faculty Development Fund (2016 and 2017), University of Houston.

Author Contributions: All authors equally contributed to this work.

Conflicts of Interest: The authors declare no conflict of interest.

\section{Abbreviations}

$\begin{array}{ll}\text { AM1 } & \text { Austin model 1 } \\ \text { BPs } & \text { Biophenols } \\ \text { BPsecos } & \text { Biophenols and secoiridoids } \\ \text { CAD } & \text { Collision activated dissociations } \\ \text { FAB } & \text { Fast atom bombardment } \\ \text { HF } & \text { Hartree-fock } \\ \text { HOMO } & \text { Highest occupied molecular orbital } \\ \text { HPLC-ESI-MS } & \text { High performance liquid chromatography electron spray ionization mass spectrometry } \\ \text { IRESMO } & \text { Istituto di ricerche europee in scienze molecolari } \\ \mathrm{H}_{2} \mathrm{SO}_{4} & \text { Sulphuric acid } \\ \text { LUMO } & \text { Lowest unoccupied molecular orbital } \\ \text { MS } & \text { Mass spectrometry } \\ \text { MEMEG } & \text { Molecular ecology, microbial ecology and evolutionary genetics } \\ \text { NMR } & \text { Nuclear magnetic resonance } \\ \text { OGlu } & \text { Glucose } \\ \text { PPO } & \text { Polyphenol oxidase } \\ \text { SCF } & \text { Semi-empirical self-consistent-field }\end{array}$




\section{References}

1. López de Las Hazas, M.C.; Piñol, C.; Macià, A.; Motilva, M.J. Hydroxytyrosol and the colonic metabolites derived from virgin olive oil intake induce cell cycle arrest and apoptosis in colon cancer cells. J. Agric. Food Chem. 2017. [CrossRef] [PubMed]

2. Sivakumar, G.; Briccoli Bati, C.; Uccella, N.A. HPLC-MS screening of the antioxidant profile of Italian olive cultivars. Chem. Nat. Compd. 2005, 41, 588-591. [CrossRef]

3. Sánchez de Medina, V.; Miho, H.; Melliou, E.; Magiatis, P.; Priego-Capote, F.; Luque de Castro, M.D. Quantitative method for determination of oleocanthal and oleacein in virgin olive oils by liquid chromatography-tandem mass spectrometry. Talanta 2017, 162, 24-31. [CrossRef] [PubMed]

4. Fabiani, R. Anti-cancer properties of olive oil secoiridoid phenols: A systematic review of in vivo studies. Food Funct. 2016, 7, 4145-4159. [CrossRef] [PubMed]

5. Ramírez, E.; Brenes, M.; García, P.; Medina, E.; Romero, C. Oleuropein hydrolysis in natural green olives: Importance of the endogenous enzymes. Food Chem. 2016, 206, 204-209. [CrossRef] [PubMed]

6. Sivakumar, G.; Briccoli Bati, C.; Uccella, N. Demethyloleuropein and $\beta$-glucosidase activity in olive fruits. Biotechnol. J. 2007, 2, 381-385. [CrossRef] [PubMed]

7. Peyrol, J.; Riva, C.; Amiot, M.J. Hydroxytyrosol in the prevention of the metabolic syndrome and related disorders. Nutrients 2017, 9, E306. [CrossRef] [PubMed]

8. Lamy, S.; Ben Saad, A.; Zgheib, A.; Annabi, B. Olive oil compounds inhibit the paracrine regulation of TNF- $\alpha$-induced endothelial cell migration through reduced glioblastoma cell cyclooxygenase-2 expression. J. Nutr. Biochem. 2016, 27, 136-145. [CrossRef] [PubMed]

9. Koudounas, K.; Banilas, G.; Michaelidis, C.; Demoliou, C.; Rigas, S.; Hatzopoulos, P. A defence-related Olea europaea $\beta$-glucosidase hydrolyses and activates oleuropein into a potent protein cross-linking agent. J. Exp. Bot. 2015, 66, 2093-2106. [CrossRef] [PubMed]

10. Di Francesco, A.; Falconi, A.; di Germanio, C.; Di Bonaventura, M.V.M.; Costa, A.; Caramuta, S.; del Carlo, M.; Compagnone, D.; Dainese, E.; Cifani, C.; et al. Extravirgin olive oil up-regulates $\mathrm{CB}_{1}$ tumor suppressor gene in human colon cancer cells and in rat colon via epigenetic mechanisms. J. Nutr. Biochem. 2015, 26, $250-258$. [CrossRef] [PubMed]

11. Hachicha Hbaieb, R.; Kotti, F.; Cortes-Francisco, N.; Caixach, J.; Gargouri, M.; Vichi, S. Ripening and storage conditions of Chétoui and Arbequina olives: Part II. Effect on olive endogenous enzymes and virgin olive oil secoiridoid profile determined by high resolution mass spectrometry. Food Chem. 2016, 210, 631-639. [CrossRef] [PubMed]

12. Hachicha Hbaieb, R.; Kotti, F.; García-Rodríguez, R.; Gargouri, M.; Sanz, C.; Pérez, A.G. Monitoring endogenous enzymes during olive fruit ripening and storage: Correlation with virgin olive oil phenolic profiles. Food Chem. 2015, 174, 240-247. [CrossRef] [PubMed]

13. Uccella, N.A. Olive biophenols: Biomolecular characterization, distribution and phytoalexin histochemical localization in the drupes. Trends Food Sci. Technol. 2001, 11, 315-327. [CrossRef]

14. Uccella, N.A. Olive biophenols: Novel ethnic and technological approach. Trends Food Sci. Technol. 2001, 11, 328-339. [CrossRef]

15. Vekey, K.; Malorni, A.; Pòcsfalvi, G.; Piperno, A.; Romeo, G.; Uccella, N.A. Biophenol-protein supramolecular models by fast atom bombardment-mass spectrometry experiments. J. Agric. Food Chem. 1997, 45, $2447-2451$. [CrossRef]

16. Bianco, A.D.; Piperno, A.; Romeo, G.; Uccella, N.A. NMR experiments of oleuropein biomimetic hydrolysis. J. Agric. Food Chem. 1999, 47, 3665-3668. [CrossRef] [PubMed]

17. Gentile, L.; Uccella, N.A. Selected bioactives from callus cultures of olives (Olea europaea L. Var. Coratina) by LC-MS. Food Res. Internat. 2014, 55, 128-136. [CrossRef]

18. Karkoula, E.; Skantzari, A.; Melliou, E.; Magiatis, P. Quantitative measurement of major secoiridoid derivatives in olive oil using qNMR. Proof of the artificial formation of aldehydic oleuropein and ligstroside aglycon isomers. J. Agric. Food Chem. 2014, 62, 600-607. [PubMed]

19. Casado-Díaz, A.; Anter, J.; Müller, S.; Winter, P.; Quesada-Gómez, J.M.; Dorado, G. Transcriptomic analyses of the anti-adipogenic effects of oleuropein in human mesenchymal stem cells. Food Funct. 2017, 8, 1254-1270. [CrossRef] [PubMed] 
20. Oi-Kano, Y.; Iwasaki, Y.; Nakamura, T.; Watanabe, T.; Goto, T.; Kawada, T.; Watanabe, K.; Iwai, K. Oleuropein aglycone enhances UCP1 expression in brown adipose tissue in high-fat-diet-induced obese rats by activating $\beta$-adrenergic signaling. J. Nutr. Biochem. 2017, 40, 209-218. [CrossRef] [PubMed]

21. Casamenti, F.; Stefani, M. Olive polyphenols: New promising agents to combat aging-associated neurodegeneration. Expert Rev. Neurother. 2017, 17, 345-358. [CrossRef] [PubMed]

22. Piroddi, M.; Albini, A.; Fabiani, R.; Giovannelli, L.; Luceri, C.; Natella, F.; Rosignoli, P.; Rossi, T.; Taticchi, A.; Servili, M.; Galli, F. Nutrigenomics of extra-virgin olive oil: A review. Biofactors 2017, 43, 17-41. [CrossRef] [PubMed]

23. Martorell, M.; Forman, K.; Castro, N.; Capó, X.; Tejada, S.; Sureda, A. Potential therapeutic effects of oleuropein aglycone in Alzheimer's disease. Curr. Pharm. Biotechnol. 2016, 17, 994-1001. [CrossRef] [PubMed]

24. Bigagli, E.; Cinci, L.; Paccosi, S.; Parenti, A.; D’Ambrosio, M.; Luceri, C. Nutritionally relevant concentrations of resveratrol and hydroxytyrosol mitigate oxidative burst of human granulocytes and monocytes and the production of pro-inflammatory mediators in LPS-stimulated RAW 264.7 macrophages. Int. Immunopharmacol. 2017, 43, 147-155. [CrossRef] [PubMed]

25. Pantano, D.; Luccarini, I.; Nardiello, P.; Servili, M.; Stefani, M.; Casamenti, F. Oleuropein aglycone and polyphenols from olive mill waste water ameliorate cognitive deficits and neuropathology. Br. J. Clin. Pharmacol. 2017, 83, 54-62. [CrossRef] [PubMed]

26. Bertolini, T.; Vicentini, L.; Boschetti, S.; Andreatta, P.; Gatti, R. A novel liquid chromatography method using diode-array detector for the determination of oleuropein in dietary supplements. J. Pharm. Biomed. Anal. 2016, 129, 198-202. [CrossRef] [PubMed]

27. Lemonakis, N.; Mougios, V.; Halabalaki, M.; Skaltsounis, A.L.; Gikas, E. A novel bioanalytical method based on UHPLC-HRMS/MS for the quantification of oleuropein in human serum. Application to a pharmacokinetic study. Biomed. Chromatogr. 2016, 30, 2016-2023. [CrossRef] [PubMed]

28. Kano, S.; Komada, H.; Yonekura, L.; Sato, A.; Nishiwaki, H.; Tamura, H. Absorption, metabolism, and excretion by freely moving rats of 3,4-DHPEA-EDA and related polyphenols from olive fruits (Olea europaea). J. Nutr. Metab. 2016, 2016, 9104208. [CrossRef] [PubMed]

29. Ricciutelli, M.; Marconi, S.; Boarelli, M.C.; Caprioli, G.; Sagratini, G.; Ballini, R.; Fiorini, D. Olive oil polyphenols: A quantitative method by high-performance liquid-chromatography-diode-array detection for their determination and the assessment of the related health claim. J. Chromatogr. A 2017, 1481, 53-63. [CrossRef] [PubMed]

30. Furia, E.; Nardi, M.; Sindona, G. Standard potential and acidic constants of oleuropein. J. Chem. Eng. Data 2010, 55, 2824-2828. [CrossRef]

31. Brenes, M.; Garcia, A.; Garrido, A. Acid hydrolysis of secoiridoid aglycones during storage of virgin olive oil. J. Agric. Food Chem. 2001, 49, 5609-5614. [CrossRef] [PubMed]

32. Perri, E.; Raffaelli, A.; Sindona, G. Quantitation of oleuropein in virgin olive oil by ion spray mass spectrometry-selected reaction monitoring. J. Agric. Food Chem. 1999, 47, 4156-4160. [CrossRef] [PubMed]

33. De Nino, A.; di Donna, L.; Mazzotti, F.; Muzzalupo, E.; Perri, E.; Sindona, G.; Tagarelli, A. Absolute method for the assay of oleuropein in olive oils by atmospheric pressure chemical ionization tandem mass spectrometry. Anal. Chem. 2005, 77, 5961-5964. [CrossRef] [PubMed]

34. Ryan, D.; Robards, K.; Prenzler, P.; Jardine, D.; Herlt, T.; Antolovich, M. Liquid chromatography with electron ionization mass spectrometry detection of phenolic compounds from Olea europea. J. Chromatogr. A 1999, 855, 529-537. [CrossRef]

35. Obied, H.K.; Bedgood, D.R.; Prenzler, P.D.; Robards, K. Chemical screening of olive biophenols extracts by hyphenated liquid chromatography. Anal. Chim. Acta 2007, 603, 176-189. [CrossRef] [PubMed]

36. Capozzi, F.; Piperno, A.; Uccella, N.A. Oleuropein site selective hydrolysis by technomimetic nuclear magnetic resonance experiments. J. Agric. Food Chem. 2000, 48, 1623-1629. [CrossRef] [PubMed]

37. Romero, C.; Brenes, M.; Garcia, P.; Garrido, A. Effect of amino acid on the chemical oxidation of olive o-diphenols in model systems. Food Chem. 1998, 63, 319-324. [CrossRef]

38. Ramírez, E.; Brenes, M.; de Castro, A.; Romero, C.; Medina, E. Oleuropein hydrolysis by lactic acid bacteria in natural green olives. LWT Food Sci. Technol. 2017, 78, 165-171. [CrossRef] 
39. Cardoso, S.M.; Guyot, S.; Marnet, N.; Lopes-da-Silva, J.A.; Renard, M.G.C.; Coimbra, M.A. Characterization of phenolic extracts from olive pulp and olive pomace by electrospary mass spectrometry. J. Sci. Food Agric. 2005, 85, 21-32. [CrossRef]

40. Cardoso, S.M.; Guyot, S.; Marnet, N.; Lopes-da-Silva, J.A.; Silva, A.M.S.; Renard, M.G.C.; Coimbra, M.A. Identification of oleuropein oligomers in olive pulp and pomace. J. Sci. Food Agric. 2006, 86, 1495-1502. [CrossRef]

41. Vogna, D.; Pezzella, A.; Panzanella, L.; Napolitano, A.; d'Ischia, M. Oxidative chemistry of hydroxytyrosol: Isolation and characterization of novel methanoxocinobenzodioxinone derivatives. Tetrahedron Lett. 2003, 44, 8289-8292. [CrossRef]

42. Paz Romero, M.; Tovar, M.J.; Girona, J.; Motilva, M.J. Changes in the HPLC phenolic profile of virgin olive oil from young trees (Olea europea L. cv. Arbequina) grown under different deficit irrigation strategies. J. Agric. Food Chem. 2002, 50, 5349-5354. [CrossRef]

43. Capasso, R.; Evidente, A.; Visca, C.; Gianfreda, L.; Maremonti, M.; Greco, G. Production of glucose and bioactive aglycone by chemical and enzymatic hydrolysis of purified oleuropein from Olea europea. Appl. Biochem. Biotech. 1996, 61, 365-377. [CrossRef]

44. Delgado-Povedano, M.M.; Priego-Capote, F.; de Castro, M.D.L. Selective ultrasound-enhanced enzymatic hydrolysis of oleuropein to its aglycon in olive (Olea europaea L.) leaf extracts. Food Chem. 2017, 220, $282-288$. [CrossRef] [PubMed]

45. Bianco, A.D.; Jensen, S.R.; Olesen, J.; Passacantilli, P.; Ramunno, A. Acid rearrangement of secoiridoid related to oleuropein and secologanin. Eur. J. Org. Chem. 2003, 22, 4349-4354. [CrossRef]

46. Alagna, F.; Geu-Flores, F.; Kries, H.; Panara, F.; Baldoni, L.; O'Connor, S.E.; Osbourn, A. Identification and characterization of the iridoid synthase involved in oleuropein biosynthesis in olive (Olea europaea) fruits. J. Biol. Chem. 2016, 291, 5542-5554. [CrossRef] [PubMed]

47. Ortega-Garcia, F.; Blanco, S.; Peinado, M.A.; Peragon, J. Polyphenol oxidase and its relationship with oleuropein concentration in fruits and leaves of olive (Olea europea) cv. "Picual" trees during fruit ripening. Tree Physiol. 2008, 28, 45-54. [CrossRef] [PubMed]

48. Gikas, E.; Papadopoulos, N.; Tsarbopoulos, A. Kinetic study of the acidic hydrolysis of oleuropein, the major bioactive metabolite of olive oil. J. Liq. Chromatogr. Relat. Technol. 2006, 29, 497-508. [CrossRef]

49. Saija, A.; Uccella, N.A. Olive biophenols: Functional effects on human wellbeing. Trends Food Sci. Technol. 2001, 11, 357-363. [CrossRef]

50. Procopio, A.; Alcaro, S.; Nardi, M.; Oliverio, M.; Ortuso, F.; Sacchetta, P.; Pieragostino, D.; Sindona, G. Synthesis, biological evaluation, and molecular modeling of oleuropein and its semi synthetic derivatives as cyclooxygenase inhibitors. J. Agric. Food Chem. 2009, 57, 11161-11167. [CrossRef] [PubMed]

51. Erkoc, F.; Keskin, N.; Rrkoc, S. Theoretical investigation of hydroxytyrosol and its radicals. J. Mol. Struct. 2003, 625, 87-94. [CrossRef]

52. Rietjens, S.J.; Bast, A.; Haenen, G.R.M.M. New insights into controversies on the antioxidant potential of the olive oil antioxidant hydroxytyrosol. J. Agric. Food Chem. 2007, 55, 7609-7614. [CrossRef] [PubMed]

53. Piperno, A.; Toscano, M.R.; Uccella, N.A. The Cannizzaro-like metabolites of secoiridoid glucosides in olive. J. Sci. Food Agric. 2004, 84, 341-349. [CrossRef]

54. Nardi, M.; Bonacci, S.; de Luca, G.; Maiuolo, J.; Oliverio, M.; Sindona, G.; Procopio, A. Biomimetic synthesis and antioxidant evaluation of 3,4-DHPEA-EDA [2-(3,4-hydroxyphenyl) ethyl (3S,4E)-4-formyl-3-(2-oxoethyl)hex-4-enoate]. Food Chem. 2014, 162, 89-93. [CrossRef] [PubMed]

55. Deslongchamps, P.; Dory, Y.L.; Li, S. The relative rate of hydrolysis of a series of acyclic and six-membered cyclic acetals, ketals, othoesters, and orthocarbonates. Tetrahedron 2000, 56, 3533-3537. [CrossRef]

56. Bianco, A.D.; Muzzalupo, I.; Piperno, A.; Romeo, G.; Uccella, N.A. Bioactive derivatives of oleuropein from olive fruits. J. Agric. Food Chem. 1999, 47, 3531-3534. [CrossRef] [PubMed]

57. De Nino, A.; Mazzotti, F.; Perri, E.; Procopio, A.; Raffaelli, A.; Sindona, G. Virtual freezing of the hemiacetal-aldehyde equilibrium of the aglycones of oleuropein and ligstroside in olive oils from Carolea and Coratina cultivars by ionspray ionization tandem mass spectrometry. J. Mass Spectrom. 2000, 35, 461-467. [CrossRef]

58. Yuan, J.J.; Wang, C.Z.; Ye, J.Z.; Tao, R.; Zhang, Y.S. Enzymatic hydrolysis of oleuropein from Olea europea (Olive) leaf extract and antioxidant activities. Molecules 2015, 20, 2903-2921. [CrossRef] [PubMed] 
59. Navarro, M.; Fiore, A.; Fogliano, V.; Morales, F.J. Carbonyl trapping and antiglycative activities of olive oil mill wastewater. Food Funct. 2015, 6, 574-583. [CrossRef] [PubMed]

60. Sivakumar, G.; Uccella, N.A. Olive biophenols and conventional biotechnology from Mediterranean aliment culture. In Olives and Olive Oil in Health and Disease Prevention; Preedy, V.R., Watson, R.R., Eds.; Elsevier Inc.: New York, NY, USA, 2010; pp. 333-340.

61. Romero, C.; Medina, E.; Mateo, M.A.; Brenes, M. Quantification of bioactive compounds in Picual and Arbequina olive leaves and fruit. J. Sci. Food Agric. 2017, 97, 1725-1732. [CrossRef] [PubMed]

62. Gutierrez-Rosales, F.; Romero, M.P.; Casanovas, M.; Motilva, M.J.; Mínguez-Mosquera, M.I. $\beta$-Glucosidase involvement in the formation and transformation of oleuropein during the growth and development of olive fruits (Olea europaea L. cv. Arbequina) grown under different farming practices. J. Agric. Food Chem. 2012, 60, 4348-4358. [CrossRef] [PubMed]

63. Paradiso, V.M.; di Mattia, C.; Giarnetti, M.; Chiarini, M.; Andrich, L.; Caponio, F. Antioxidant behavior of olive phenolics in oil-in-water emulsions. J. Agric. Food Chem. 2016, 64, 5877-5886. [CrossRef] [PubMed]

64. Aggoun, M.; Arhab, R.; Cornu, A.; Portelli, J.; Barkat, M.; Graulet, B. Olive mill wastewater microconstituents composition according to olive variety and extraction process. Food Chem. 2016, 209, 72-80. [CrossRef] [PubMed]

65. Schweigert, N.; Zehnder, A.J.B.; Eggen, R.I. Chemical properties of catechols and their molecular modes of toxic action in cells from microorganisms to mammals. Environ. Microbiol. 2001, 3, 81-91. [CrossRef] [PubMed]

66. Dammak, I.; Neves, M.A.; Nabetani, H.; Isoda, H.; Sayadi, S.; Nakajima, M. Effect of pH condition on the retention of oleuropein in aqueous solution by nanofiltration membrane. Sep. Sci. Technol. 2014, 49, 2289-2302. [CrossRef]

67. Câmara, C.P.P.; Bortoloti, J.; Scarminio, I.S.; Ballus, C.A.; Meinhart, A.D.; Godoy, H.D.; Bruns, R.E. Optimization of electrophoretic separations of thirteen phenolic compounds using single peak responses and an interactive computer technique. J. Braz. Chem. Soc. 2013, 24, 1744-1753. [CrossRef]

(C) 2017 by the authors. Licensee MDPI, Basel, Switzerland. This article is an open access article distributed under the terms and conditions of the Creative Commons Attribution (CC BY) license (http://creativecommons.org/licenses/by/4.0/). 